\title{
Kommunikation og organisation af viden \\ - et medieteoretisk perspektiv
}

\author{
Af Jack Andersen
}

\section{Indledning}

Denne artikel har, som titlen antyder, til hensigt at belyse kommunikation og vidensorganisation udfra et medieteoretisk perspektiv. Dette gøres ved at tage udgangspunkt i nogle værker af nogle udvalgte medieteoretikere. Formålet er todelt. Dels at introducere dele af disse medieteoretikeres forfatterskab omkring emnet og dels, at ind ette dette i en bredere biblioteks- og informationsvidenskabelig ramme for vidensorganisation. Det sidste nødvendigg øres af biblioteks- og informationsvidenskabens til tider meget snævre opfattelse af, hvad vidensorganisation er. Megen biblioteks- og informationsvidenskabelig forskning i vidensorganisation giver på den ene side udtryk for vigtigheden af det kommunikative aspekt i vidensorganisation. På den anden side negligeres kommunikationens sociokulturelle bundethed, som ellers næsten tages for givet af de este andre humanistiske og samfundsvidenskabelige discipliner, der beskæftiger sig med kommunikation.

Formålet med dette perspektiv er at belyse det biblioteks- og informationsvidenskabelige vidensorganisationsbegreb og dets historicitet; dvs. hvilken tra- dition begrebet er et produkt af. Dette vil belyse vidensorganisationens mulighedsbetingelser i forskellige menneskelige symbolsystemer, som f.eks. mundtlige- og skriftlige kulturer, og hvordan dette kan ses som et middel til at strukturere en social orden.

Indenfor de senere år har ere forskere indenfor biblioteks- og informationsvidenskab diskuteret og argumenteret for vigtigheden af mere historiske, sociale, kulturelle og sociale tilgange til viden og vidensorganisation (f.eks. Albrechtsen \& Jacob, 1999; Bowker \& Star, 1999; Hansson, 1996, 1999; Hjørland, 1997, 1998; Hjørland \& Albrechtsen, 1999; Jacob \& Shaw, 1998; Mai, 1999, 2000; Olson, 1999, 2000). Disse tilgange bør ses som yderst velkomne. Men når talen falder på vidensorganisation og dets kommunikative formål, er der ikke mange tilgange, der har taget kommunikations- eller medieperspektiver i betragtning.

Hensigten med denne artikel er således at kortlægge det biblioteks- og informationsvidenskabelige vidensorganisationsbegreb i relation til midlerne og måderne, hvorpå der kommunikeres i sam- 
fundet. Dette vil blive gjort ved at anlægge et medieteoretisk perspektiv. Dette perspektiv er bl.a. udviklet af den amerikanske medieforsker Joshua Meyrowitz (1994), men har sine rødder i den canadiske 'Toronto school' repræsenteret specielt ved Marshall McLuhan's (McLuhan, 1962; 1964) og Harold A. Innis (Innis, 1995; [1951)). Et sådant perspektiv skal hjælpe til at afdække både vidensorganisationens mulighedsbetingelser i kulturer og samfund med og uden forskellige former for kommunikationsteknologier, samt hvordan det har været og er et middel til strukturere en social orden.

Hensigten er således at belyse vidensorganisationsbegrebets historicitet og hvordan det er konstitueret af den sociale organisation af viden. På denne led vil jeg fors $\emptyset \mathrm{ge}$ at afdække, hvordan organisation og repræsentation af dokumenter i informationssystemer kan ses som en a edt måde af samfundets fors $\emptyset \mathrm{g}$ på at organisere sig selv igennem dets brug af forskellige måder og midler til kommunikation.

På denne led er tesen, som skal blive forfulgt i det følgende, den, at det biblioteks- og informationsvidenskabelige vidensorganisationsbegreb er underlagt, og er del af, en bredere social organisation af viden i samfundet, og at ethvert forsøg på at organisere viden i informationssystemer kan forstås i lyset af kommunikationsmåderne i samfundet. Ved at se på det biblioteks- og informationsvidenskabelige vidensorganisationsbegreb i dette lys kan måske yderligere forklare, hvorfor og hvordan vidensorganisationens opgave er at bidrage til at kunne identificere ,the best textual means to an end" (Wilson, 1968, p. 21) eller ,the epistemological or informative potentials of documents“ (Hjørland, 1992, 1997, p. 86). Denne praksis kan imidlertid ikke foretages uden at tage de aktiviteter i betragtning, som dokumenter er udviklet til at tjene eller blive anvendt indenfor. Betragtet således er dokumenter redskaber udviklet til at betjene forskellige kommunikative behov og formål med henblik på at blive brugt i forskellige socio-kommunikative aktiviteter eller sammenhænge. Disse aktiviteter er i stor udstrækning socialt organiseret og betjener sig af forskellige kommunikations- teknologier til at strukturere denne sociale organisering. Med andre ord: Organisering og repræsentation af dokumenter i informationssystemer er et udtryk for en tilpasning og støtte til disse forskellige aktiviteter. Dette viser til en hvis grad betydningen af at tage den sociale organisation af viden i betragtning, når man organiserer dokumenter i informationssystemer.

I det følgende vil jeg derfor argumentere for at en væsentlig baggrund for vidensorganisationens historiske grundlag, er at se på, hvordan viden er blevet og bliver søgt efter og lagret; dvs. hvordan viden (eller information) bliver kommunikeret. Jeg hævder ikke, dette er den eneste måde at spore det biblioteks- og informationsvidenskabelige vidensorganisationsbegreb, men betoner, at en analyse af dette begrebs historicitet kan fordelagtiggøres ved at belyse, hvordan viden eller en kulturs (et samfunds) kulturelle kapital bliver lagret og kommunikeret. Dette kan forhåbentlig yderligere bidrage til en forklaring af de sociokulturelle og tekstuelle faktorer, der fører til forestillingen om vidensorganisation i en biblioteks- og informationsvidenskabelig sammenhæng, samt tilbyde en forståelsesramme for den rolle, som denne form for vidensorganisation måtte have spillet i sociale og kulturelle praksisser, i det omfang disse er betinget af diverse former for kommunikationsteknologier. Hvad en given kultur kan genfinde af viden, og hvad eftertiden kan arve, er afhængig af, hvilke måder og midler man gør brug til lagring af viden og information. Udviklingen af bibliografiske klassifikationssystemer og katalogiseringsregler er født ud af denne historie. På denne led det biblioteks- og informationsvidenskabelige vidensorganisationsbegreb grundlæggende født ud af historien om den sociokulturelle udvikling af samfundet og hvordan det organiserer sig selv.

Overfor dette kan der blive indvendt, at dette var, hvad Margaret Egan \& Jesse Shera (1952) prøvede på at komme frem til, da de i sin tid argumenterede for deres 'social epistemology' som 'the analysis of the production, distribution, and consumption of intellectual products' og det bibliografiske systems 
rolle i den sociale kommunikation af viden. På denne måde indså de det vigtige forhold mellem kommunikative handlen og vidensorganisation og betonede sidstnævnte som en del af en bredere sociokommunikativ aktivitet (dvs. produktionen, distributionen og forbrugen af 'intellectual products'). Men hvad Egan and Shera (1952) ikke gjorde, var at lægge vægt på de historiske aspekter af denne kommunikative handlen og vidensorganisationens forhold heri.

For at belyse vidensorganisationsbegrebets historicitet synes det derfor rimeligt at gøre dette i lyset af specifikke kommunikationsteknologier. I denne artikel vil disse være skriften, trykkepressen og computeren. De er eksempler på kommunikationsteknologier, der har haft, og stadig har, en direkte ind ydelse på enhver form for biblioteks- og informationsvirksomhed, fordi de på hver deres måde, qua deres unikke karakteristika, har påvirket og forandret måden at producere, distribuere og bruge dokumenter på. Jeg vil således ikke tage andre kommunikationsteknologier som f.eks. telefonen, radioen eller fjernsynet i betragtning, selvom deres sociale og kulturelle ind ydelse ikke kan undervurderes. Men hårdt sat op, har de ikke haft en så afgørende ind ydelse på biblioteks- og informationsvirksomhed som de førstnævnte kommunikationsteknologier.

Artiklen er struktureret på følgende måde. Først vil jeg kort beskrive for det medieteoretiske perspektiv. Dette bliver fulgt op af en redegørelse for, hvordan vidensorganisationsbegrebet opfattes i en biblioteks- og informationsvidenskabelig sammenhæng. Dernæst bliver vidensorganisationens historiske mulighedsbetingelser belyst fra forskellige perspektiver som oralitet, skriften, trykkepressen og computeren. Hovedtræk ved disse perspektiver bliver beskrevet og vidensorganisationsbegrebet belyst i forhold hertil. Hensigten er her ikke blot at vise, at hver af disse kommunikationsteknologier har specielle karakteristika, hvad angår kommunikation og organisation af viden, men at søge at argumentere for, at den måde de indvirker på den sociale organisation af samfundet også virker tilbage på og er en forudsætning for tanken om vidensorganisation i biblioteks- og informationsvidenskabelig sammenhæng.

Perspektivet omkring de mundtlige kulturer synes nødvendigt i denne sammenhæng. Walter Ong (1982, p. 78) har f.eks. argumenteret for, at man ikke kan komme til en forståelse af struktureringen af viden i skriftkulturer, og kulturer der bygger på denne, uden en tilsvarende indsigt i dens modsætning $\mathrm{i}$ mundtlige kulturer, fordi måden hvorpå viden bliver struktureret her, er så radikalt anderledes sammenlignet med skriftkulturer.

\section{Medieteori}

Medieteoretikeren Joshua Meyrowitz argumenterer i hans essay 'Medium Theory' for, hvorfor han har valgt entalstermen medie og ikke ertalstermen 'media'. Han kritiserer megen 'media theory' for at være for meget beskæftiget med indholdet af 'media messages' og deres indvirkning på folk i diverse situationer. Godt nok anerkender Meyrowitz 'media theory' i denne udformning, men det udtømmer ikke billedet efter hans mening. 'Medium theory' er derfor beskæftiget med

„...the particular characteristics of each individual medium or of each particular type of media. Broadly speaking, medium theorists ask: What are the relatively fixed features of each means of communicating and how do these features make the medium physically, psychologically, and socially different from other media and from faceto-face interaction?" (p. 50)

På denne led ser Meyrowitz altså 'medium theory' som værende beskæftiget med forskellige kommunikationsteknologiers særlige egenskaber med henblik på, hvordan de forandrer indholdet af, hvad der kommunikeres. Midler til og måder at kommunikere på i forskellige kulturer og civilisationer er afhængig af de kommunikationsteknologier, der til rådighed. Som medieforsker tænker Meyrowitz naturligvis på det biblioteks- og informationsvidenskabelige vidensorganisationsbegreb. Men på et makroniveau 
fremfører han, medieteori ('medium theory') har til hensigt at analysere, hvilke virkninger en ny kommunikationsmåde har i forhold til allerede etablerede medieformer i samfundet og hvordan denne omformer sociale interaktioner og sociale strukturer. (Meyrowitz, 1994, p. 51). I denne henseende, anerkender 'medium theory', at forskellige kommunikationsmedier har visse indvirkninger og ændrer måske den samfundsmæssige organisering. Med andre ord: At der er en stærk sammenhæng mellem kommunikationsmedier og den samfundsmæssige organisering de formidler, reagerer på og omformer.

Meyrowitz benævner nogle af de medieteoretikere, som der trækkes på i denne artikel, som „First-generation medium theorists". På trods af deres forskellige dagsordner, tilgange og konklusioner, er fællesnævneren mellem dem, ifølge Meyrowitz, at:

,... a surprisingly consistent and clear image of the interaction of media and culture emerges. Broadly speaking, theses theorists' works cohere into a shared image of three phases of civilization matched to three major forms of communicating: the move from traditional oral societies to modern print societies (via a transitional scribal phase), to an electronic global culture.“ (p. 53)

I det følgende vil værker af David J. Bolter (2001), Elizabeth Eisenstein (1979), Niels Ole Finnemann (1999a, 1999b), Jack Goody (1977, 1986, 1987, 2000), Jack Goody og Ian Watt (1963), og Walter Ong (1982), blive brugt i analysen. Disse teoretikere analyserer fra forskellige synspunkter og udgangspunkter overgangen fra mundtlige kulturer til skriftkulturer og trykkepressen og computeren med henblik på, hvad det indebærer for kommunikation og organisering af viden i samfundet. En gennemgang af det biblioteks- og informationsvidenskabelige vidensorganisationsbegreb i lyset af dette medieteoretiske perspektiv vil således belyse, hvordan begrebet kan ses værende vokset ud af interaktionen mellem medier og kultur.

\section{Den biblioteks- og informationsvidenskabelige kontekst}

Indenfor biblioteks- og informationsvidenskab eksisterer der en lang tradition for studiet af vidensorganisation. Med undtagelse af f.eks. With the Henry Evelyn Bliss (1929), Egan og Shera (1952), Patrick Wilson $(1968 ; 1977 ; 1983)$ og Birger Hjørland (1994, 1997), der alle har argumenteret for og analyseret vidensorganisationens rolle i forhold til samfundets produktion og kommunikation af viden, har denne tradition været karakteriseret ved en søgen efter teknikker, standarder og regler for vidensorganisation frem for at have stræbt imod en forståelse af dens rolle i netop samfundets produktion og kommunikation af viden. Hvis dette havde været tilfældet, ville begrebsliggørelsen af vidensorganisation vel have set lidt anderledes end det f.eks. gør i lærebøger som Hagler (1997), Lancaster (1998), Rowley (1992), Svenonius (2000), og Taylor (1999). Resultatet er derfor en temmelig snæver opfattelse af vidensorganisation indenfor biblioteks- og informationsvidenskab, som næsten konsekvent ignorerer den bredere sociale organisation af viden, som er en betingelse for den biblioteks- og informationsvidenskabelige form for vidensorganisation. I en artikel i International Encyclopedia of Library and Information Science om 'Vidensorganisation' giver James Anderson (1996) eksplicit udtryk for denne smalle opfattelse:

„The description of documents, their content, features and purpose, and the organization of these description so as to make these documents and their parts accessible to persons seeking them or the messages that they contain. Knowledge organization encompasses every type and method of indexing, abstracting, cataloguing, classification, records management, bibliography and the creation of textual or bibliographic databases for information retrieval ... In the context of library and information science, the organization of knowledge (often called the organization of information) is the organization of documented 
messages in which knowledge or information is represented.“ (p. 336)

Denne opfattelse af vidensorganisation mangler at tage i betragtning den rolle, som den sociale organisation af viden spiller. Hjørland formulerer det meget præcist, hvad denne dækker over:

„...knowledge is organized in learned institutions, in professionals, in journals, in libraries, and so on. Knowledge is produced as a part of human activity and tied to the division of labor in society. “ (Hjørland 1997, p. 45)

Den opfattelse af den sociale organisation af viden, som den her er refereret til af Hjørland, viser dens forbindelse med menneskelige kommunikative aktiviteter. Dokumenterne der f.eks. skal organiseres og repræsenteres i informationssystemer er et resultat af en allerede etableret social organisation af viden (f.eks. disciplinære organisering af den videnskabelige vidensproduktion (se også Burke, 2000, pp. 81115)), som kan betragtes som en organisering af én form for menneskelig aktivitet. Denne menneskelige aktivitet, defineret af Karpatschof (2000, p. 184) som "...the societally-formed life process realized through the actions of the individuals participating in it" er karakteriseret ved produktionen og brugen værktøjer som eksempelvis dokumenter.

Endvidere, i en nylig publiceret bog omhandlende vidensorganisationens intellektuelle grundlag, og med henblik på vidensorganisationens historiske kontekst, skriver forfatteren, Elaine Svenonius, at : „The relevant background is the tradition of AngloAmerican descriptive and subject cataloging during the last century and a half." (Svenonius, 2000, p. 2; min fremhævelse). Selvom Svenonius vedkender, at en eller anden 'form for' vidensorganisation er foregået siden ca. 2000 år før Kristus, så begrænser hun ikke desto mindre den historiske baggrund og kontekst til de sidste 150 år, fordi de store bibliografiske klassifikationssystemer og katalogiseringsreglerne blev 'opfundet' i denne periode. Dette er jo ikke usandt. Men det historien om vidensorganisationens 'intellektuelle' grundlag en smule kort. Et sådant syn på vidensorganisation tager ikke med i sine overvejelser de sociale, historiske, kulturelle, epistemologiske og kommunikative omstændigheder, der lægger til grund for ethvert fors $\emptyset \mathrm{g}$ på at organisere viden. Et modargument hertil kunne naturligvis være at måden, hvorpå dokumenter faktisk bliver klassificeret, indekseret og katalogiseret i dag er uafhængig af, hvordan vidensorganisation bliver set på i et bredere sociohistorisk perspektiv. Men dette argument er ikke i stand til at komme med en forståelse af vidensorganisationens samfundsmæssige rolle. Denne rolle skal vedkendes. Ellers kan det blive svært for biblioteks- og informationsvidenskaben at argumentere for, at vidensorganisation gør en forskel. Et sådant argument kan ikke bare udelade historien, idet det er i historien argumentets tyngde skal findes. B $\varnothing$ ger som f.eks. Peter Burke's ,A Social History of Knowledge“ (2000) and Foster Stockwell's „A History of Information Storage and Retrieval“" (2001) er eksempler på værker, der belyser den vidensorganisationens samfundsmæssige rolle i et bredt historisk perspektiv. Desuden så er bibliografiske klassifikationssystemer og katalogiseringsregler selv et produkt af én særlig kommunikationsteknologi: Skriften. Men skriften var i første omgang en teknologi brugt til at organisere samfundet (se f.eks. Goody, 1986; Goody, 2000, pp. 132-151). Alt dette kalder på en bredere opfattelse af vidensorganisation indenfor biblioteks- og informationsvidenskab for herigennem at redegøre for og forstå dets historicitet.

\section{Mundtlige kulturer og vidensorganisation}

I hans bog „Orality and Literacy: The Technologizing of the Word“ (1982) præsenterer Walter Ong et meget klart billede af kommunikation og organisering af viden I mundtlige kulturer og hvordan det strukturer måder at tænke på. Mundtlige kulturer burger historier, poesi og beretninger til at lagre, organisere og kommunikere viden. Disse udgør mundtlige kulturers hukommelsesteknikker. De udgør midlerne og måderne til overføre til fremtidige generationer den kulturelle arv. I mundtlige kultu- 
rer ,[t]here can be no reference to 'dictionary definitions'..." (Goody \& Watt, 1963, p. 306). Selve udtrykket ,at slå noget op“ giver simpelthen ikke mening (Ong, 1982, p. 31). Udtrykket er et produkt af skriften og er grundlæggende, hvad den smalle biblioteks- og informationsvidenskabelig opfattelse af vidensorganisation fæstner lid til. At organisere og repræsentere dokumenter i informationssystemer er netop at gøre det muligt at slå noget op, at kunne dokumentere noget. Men betyder det, at mundtlige kulturer ikke er i stand til at organisere viden? Selvfølgelig ikke! At påstå dette ville være det samme som at sige, at mundtlige kulturer overhovedet ikke producerer viden. Det gør de naturligvis. Ellers ville de ikke have nogen form for social og erkendelsesmæssig udvikling, hvilket historien viser, de har haft.

Hvor der bliver produceret viden, opstår der et næsten logisk behov for at organisere viden med henblik på at kommunikere og genfinde den. Eftersom enhver kultur igennem menneskehedens historie har produceret viden, har også en mundtlig kultur en interesse i at bevare, hvad der for den er værdifuld, symbolsk viden. Som både Goody \& Watt (1963) og Ong (1982) argumenterer for, så er en mundtlig kulturs kulturelle arv er begrænset til, hvad der kan blive husket - og glemt! Hvad der kan blive husket (og genfundet) er afhængig af, hvad der kan blive lagret i den individuelle hukommelse, som historier, beretninger og poesi er det kollektive grundlag for. Den eneste måde at kommunikere viden på er igennem mundtlig overlevering. Bøger og andre materialer for nedfældning af viden eksisterer ikke. Dette har betydning for, hvordan og hvad der skal huskes. Ifølge Goody \& Watt (1963, p. 311) forklarer dette bl.a., hvorfor myte og historie smelter sammen i et, fordi disse ikke kan adskilles i mundtlige kulturer. Det eneste medie til rådighed er det talte sprog, som netop g $\varnothing \mathrm{r}$ det svært at skelne mellem myte og historie (eller realitet), når den kulturelle arv skal viderekommunikeres.

Wilson (1977, p. 34) taler om organisering af 'knowers' som vidensorganisation. I mundtlige kulturer er vidensorganisation i stor udstrækning ensbe- tydende med organisering af personer ('knowers'). Man kan kalde disse en kulturs epistemiske autoriteter. På grund af f.eks. erhvervspositioner i samfundet er disse personer centrale elementer i den sociale organisering af viden i mundtlige kulturer og bidrager på denne led til at bestemme, hvad der kan tænkes og vides. Disse personer bliver konsulteret, når noget skal dokumenteres. På denne led indtager de også magtpositioner. Dette indebærer ydermere, at når disse personer ikke er tilstede mere, er den kulturelle arv umulig at spore, med mindre den er blevet overleveret til andre personer igennem beretninger, myter, og poesien.

Den sociale gruppering af personer symboliserer derfor mundtlige kulturers informationssystemer. Lagring og genfinding af viden afhænger af, hvordan poesi, beretninger og myter er blevet kommunikeret og af hvem der har stået for kommunikationshandlingen. Disse kommunikationsgenrer formidler den sociale organiserings former og strukturerer sociale aktiviteter. Organiseringen og repræsentationen af viden i informationssystemer er således ikke adskilt i tid og rum fra dem som producerer, kommunikerer og lagrer viden. Derfor er der en stærk interaktiv sammenhæng mellem social organisering og vidensorganisation i mundtlige kulturer Viden lagret $\mathrm{i}$ informationssystemer former mundtlige kulturers sociale strukturer. På den anden side former de sociale strukturer også hvilken slags viden, der skal lagres og kan blive genfundet. For vidensorganisationens vedkommende viser denne dialektik, hvordan vidensorganisation i mundtlige kulturer er tæt forbundet med den sociale organisering af personer ('knowers'), hvilket igen viser vidensorganisationens sociopolitiske natur.

\section{Skriftkultur og vidensorganisation}

Den britiske antropolog, Jack Goody, har i adskille bøger analyseret og beskrevet de social og erkendelsesmæssige konsekvenserne indførelsen af skriften medfører for organiseringen af samfundet (se f.eks. Goody, 1977, 1986, 1987, 2000). Med fremkomsten af skriften blev mennesket vidne til en teknologi, der 
gjorde det muligt at gå udover den enkeltes hukommelse med hensyn til lagring og organisering af viden. If $\varnothing$ lge Goody (2000, p. 136), betød skriften ikke kun en ændring i kommunikationsmidlerne og måderne at kommunikere på, men også en ændring af hvad der blev kommunikeret. Skriften gjorde kommunikation mellem lange afstande i tid og rum mulig. Den gjorde muligt for en given kultur, sammenlignet med mundtlige kulturer, at bevare viden for eftertiden uden at være totalt afhængig af tid og rum og individets hukommelse:

„No longer did the problem of memory storage dominate man's intellectual life; the human mind was freed to study static 'text' (rather than be limited by participation in the dynamic 'utterance'), a process that enabled man to stand back from his creation and examine it in a more abstract, generalized, and 'rational' way."

(Goody, 1977, p. 44)

På denne led er skriften en enestående teknologi i historien om den erkendelsesmæssige og sociokulturelle udvikling af den menneskelige civilisation. I hans bog ,The Logic of Writing and the Organization of Society" (1986) beskriver og analyserer Goody betydningen af skriften for samfundets sociale struktur og institutioner. Ved at argumentere for skriftens betydning i kulturer som Mesopotamien og oldtidens Egypten for institutioner og praksisser som religion, handel, staten og loven viser Goody, hvordan disse praksisser ændres fundamentalt med brugen af skriften som kommunikationsmiddel. Disse samfundsmæssige institutioner producerer og gør brug af skriften i magthenseende og til at vedligeholde særlige praksisser (f.eks. udformning af skriftlige love og regler). Dvs. skriften er stedet, hvor den sociale interaktion foregår. Men den optimale brug af skriften i disse praksisser er afhængig af, dokumenter rent faktisk kan genfindes, hvorfor et behov for en organisering af disse opstår. På denne måde er det, at skriften giver 'fødsel' til betegnelsen nedfældet viden og igennem dette til, hvad Goody kalder tankens objektivisering (Goody, 1977, p. 44).
Nedfældet viden betyder, at viden kan akkumuleres for fremtidige generationer og kan blive udsat for kritik og brugt i dokumentationshenseende. For vidensorganisation medfører dette en yderligere eksternalisering. Mens det i mundtlige kulturer var begrænset til særlige personer, grupper eller lokaliteter, kan viden med skriftens indførsel nu organiseres i en mere stabil og fast form.

Institutioner som f.eks. biblioteker og arkiver og deres vidensorganisation er naturligvis en logisk udvidelse af og et svar på udviklingen af skriften som et middel til at strukturere diverse former for sociale aktiviteter baseret på skriften (Gaur, 1994, p. 661). Samfund og kulturer der producerer dokumenter med henblik på at bruge dem i selve organiseringen af disse samfund og kulturer er derfor også afhængig af midler til lagring og adgang til disse dokumenter. Informationssystemer (som f.eks. biblioteker eller arkiver) til organisering og repræsentation af viden er derfor en del af et større tekstuelt rum for social interaktion. På samme måde som poesi, beretninger og myter er metoderne til og genrerne for genfinding og organisering af viden i mundtlige kulturer, er disse skriftkulturer erstattet af, eller i det mindste suppleret med, andre sofistikerede metoder og genrer til genfinding og organisering af viden som f.eks. fortegnelser af forskellig karakter. Brugen af f.eks. fortegnelser i forskellige sociale praksisser (f.eks. ved brug i handler) betød bl.a., at man skulle have specielle åndskundskaber for dette. Disse kundskaber er ikke naturligt givne, hvorfor der opstår en samfundsopdeling bestående af mennesker med læse- og skrivefærdigheder og mennesker uden disse færdigheder. Dvs. organisering af viden er et resultat af og en reaktion på og støtte til én bestemt samfundsorganisering: Den lærde organisering af samfundet. At være i stand til at nedfælde noget viser, hvordan det biblioteks- og informationsvidenskabelige vidensorganisationsbegreb er knyttet til tekstualitet og igennem dette til færdigheder som læsning og skrivning. Men denne forbindelse til tekstualitet er imidlertid betinget af brugen af skriften i den sociale organisation af viden som den kommer til udtryk i samfundsinstitutionernes sociale praksisser. 
Ovennævnte kan siges at være begyndelse til det biblioteks- og informationsvidenskabelige vidensorganisationsbegreb. Begrebet kan ses værende udviklet af de omtalte sociale praksisser. Således betragtet fra skriftkulturperspektivet kan det biblioteks- og informationsvidenskabelige vidensorganisationsbegreb altså ses som et produkt af menneskets anstrengelser for at organisere dets intellektuelle aktiviteter som en del af det kundskabsbaserede samfund, skriften gav anledning.

\section{Bogtrykkerkunsten og vidensorganisation}

Elizabeth Eisenstein har i sit store værk „The Printing Press as an Agent of Change. Communications and Cultural Transformations in Early-Modern Europe" (1979) argumenteret for bogtrykkerkunstens sociale og erkendelsesmæssige betydning i 1600-tallets Europa. Ifølge Eisenstein havde bogtrykkerkunsten store konsekvenser for religion (dvs. Protestantisme), opkomsten af kapitalisme og nationalisme, og begyndelsen af moderne (natur)videnskab. Alt sammen noget der betød omvæltninger i den samfundsmæssige organisering af 1600-tallets Europa. Én stor konsekvens af bogtrykkerkunsten var den stærke manifestation af skriftlig kommunikation som et vigtigt middel til at kommunikere viden (specielt videnskabelig viden). Meyrowitz (1994, p. 55) skriver i denne henseende, at ,,print divides people into separate communication systems“. Denne 'modernisering' af skriftlig kommunikation resulterede $i$ en udvikling af tidlig offentlighedssfære og specifikke former for professionelle diskursfællesskaber, „different informational worlds“, som Meyrowitz kalder det (Meyrowitz, 1994, p. 55). Alt dette er et udtryk for en organisering af aktiviteter der medførte en specialisering i produktion og brug af viden (se f.eks. Burke, 2000, pp. 18-31). Ét eksempel på dette er udviklingen af det moderne videnskabelige kommunikationssystem med dets aktører og artefakter som for eksempel forfattere, læsere, redaktører og tekster (se f.eks. Bazerman (1988, pp. 128150) for en analyse af dette).
Ifølge Eisenstein (1979) gav bogtrykkerkunsten anledning til en ny opfattelse af forfatterbegrebet, titelbegrebet og udgavebegrebet, samt en ny medieindustri bestående af bl.a. boghandlere og forlæggere. Dette illustrerer, hvordan forskellige aktører var involveret i dokumentproduktionen, hvilket medførte, at de også blev en del af det enkelte dokument. Hvad det enkelte dokument angår, så blev disse aktører et udtryk for de tekstuelle karakteristika (forfatter, titel, udgiver og forlægger) knyttet til produktionen og identifikationen af det enkelte dokument. På denne led bidrager de til dokumentets materialitet, individualitet og offentlighed. Disse tekstuelle karakteristika bliver stadig udnyttet $\mathrm{i}$ dag, når man organiserer viden i informationssystemer som f.eks. bibliografier eller bibliotekskataloger. De udgør vigtige elementer i den bibliografiske post og medfører bl.a., at bibliografisk kontrol kan blive udøvet. Disse tekstuelle karakteristika var også en del af den reorganisering og standardisering af tekster, som f.eks. brugen af alfabetisering, fremkaldt af bogtrykkerkunsten. På denne led kan der altså spores en stærk forbindelse mellem, hvad bogtrykkerkunsten som teknologi gjorde ved tekster i form af deres organisering og produktion og hvordan dette bidrag til en ændring af organisering af tekster i informationssystemer.

Tekster var også den fremvoksende medieindustris varer. Dette betegner en ny social organisering af de kulturelle produktionsmidler, modsat produktion af tekster i skriftkulturen. Tekster kunne nu sælges på et marked, som dermed også skabte et behov for forlæggernes salgskataloger, hvori titler spillede en væsentlig rolle i identifikationen af tekster. Dette marked for tekster medførte ydermere også en mangfoldighed af tekster. For eksempel, kunne kort der illustrede de fremvoksende nationalstaters grænser nu produceres. Denne produktion af en mangfoldighed af tekster betød også, at ere mennesker end i skriftkulturen kom i kontakt med tekster som en del af deres lærings- og videnserhvervende praksisser. Biblioteket, arkivet eller en anden form for informationssystem med en organiseret samling af dokumenter blev således en støtte til disse praksis- 
ser ved at bevare og stille dokumenter til rådighed for eftertiden og genfinding. Bibliografier og indekser, der brugte alfabetisering som organiseringsprincip, blev skabt som en reaktion på disse praksisser og som en konsekvens af en ny social struktur fremkaldt af bogtrykkerkunsten. Selvom det biblioteksog informationsvidenskabelige vidensorganisationsbegreb støtter sig på skriften, har trykkepressen, mere end nogen anden kommunikationsteknologi, bidraget til en manifestering af begrebet som organisering og repræsentation of dokumenter i informationssystemer. Trykkepressen fremkaldte en kvantitativ forøgelse af dokumentproduktionen. Dette førte til forskellige former for samlinger af organiseret viden for at eftertiden skulle være i stand til at genfinde dem. De tekstuelle karakteristika nævnt ovenfor er alle midler til at sikre genfindingen. På denne led frembragte trykkepressen en ændring i det biblioteks- og informationsvidenskabelige vidensorganisationsbegreb, som er forskellig fra de ændringer skriften fremkaldte

\section{Computeren og vidensorganisation}

I det følgende skal computeren og Internettet bliver behandlet samtidigt, eftersom førstnævnte er forudsætningen for sidstnævnte. Siden 1950'erne har 'Information retrieval' (IR)-traditionen indenfor biblioteks- og informationsvidenskab været kendt forskning i brugen af computere til lagrings- og genfindingsproblematikker. Denne tradition er imidlertid ikke specielt kendt for at udvise en interesse i de sociohistoriske aspekter omkring brugen af computeren til disse problematikker. Tværtimod, på nogle punkter kan denne tradition karakteriseres ved ,... a partly unre exive response to developments in computer and telecommunications technology in the late 1940s.“ (Warner, 2001, p. 1). Helt på linie med Julian Warner (2001), vil den følgende diskussion forsøge at belyse forholdet mellem computeren og vidensorganisation som en 're exive response'.

Niels Ole Finnemann (1999a) har argumenteret for, at computeren i dag er en del af de sociale og kulturelle omvæltninger som nutidens samfund er vid- ner til. Han definerer computeren som en multi-semantisk maskine og betragter den som et medie for vidensrepræsentation. Hvad der karakteriserer computeren som medie er, ifølge Finnemann, dens omfattende evne til at varetage funktioner, der før blev særskilt varetaget af forskellige medier. Disse 'gamle' medier bliver nu i stedet genrer i den digitale computer (Finnemann, 1999b, p. 13).

Finnemann (1999a, p. 147) nævner tre særlige karakteristika ved computeren: 1) computeren er i stand til at producere, redigere, behandle, lagre, distribuere, kopiere og genfinde viden. 2) computeren er et medie til på sproglig (talt eller skriftligt) vis at præsentere formalt, billedligt og hørebaseret udtrykt viden. 3) computeren er et kommunikationsmedie (inklusiv post, telefon, radio). Som en konsekvens af disse funktioner hævder Finnemann (1999a, p. 147), at vi er ved at se begyndelsen til et globalt distribueret, elektronisk integreret vidensarkiv. Et sådant arkiv har naturligvis ind ydelse på, hvad der vides og hvad der kan findes ud af, fordi det bestemmer midlerne til at finde ud af, hvad der vides. Det er indlysende, at et sådant globalt distribueret, elektronisk integreret vidensarkiv også er en del af samfundets infrastruktur, fordi ethvert samfundet bl.a. er karakteriseret ved hvad der vides, hvad der kan findes ud af og hvordan. I det omfang dette er rigtigt, bliver det biblioteks- og informationsvidenskabelige vidensorganisationsbegreb mere end nogensinde knyttet til, hvad man kunne kalde for 'samfundets socialepistemologiske infrastruktur'. Dette ser også ud til at være Finnemanns tanker:

,Since the computer provides new ways to produce, represent, and organize knowledge in general as well as new ways of communication, it also provides a change in the societal infrastructure, in so far society is defined by the methods of knowledge representation and communication." (Finnemann, 1999a, p. 147)

Disse funktioner ved computeren som medie ser ud til at være blevet styrket og yderligere betonet med Internettet. Opkomsten af Internettet som en poten- 
tiel kilde til viden eller information medfører, at informationssøgning i dette globalt distribueret, elektronisk integreret vidensarkiv bliver mere end nogensinde en central del af samfundets sociale og kulturelle praksisser. Er dette tilfælde opstår der et behov for organiseret viden. Søgeindekser som f.eks. Yahoo er et eksempel på dette. Dette lyder måske trivielt. Men pointen er, at vidensorganisation nu skal til at tage en synlig social ansvarlighed på sig for at fuldføre sin rolle i 'samfundets socialepistemologiske infrastruktur', netop fordi mange ere mennesker er afhængig af det. Det er de lige præcis, fordi computeren, som pointeret af Finnemann (1999a, 1999b) tager sig af opgaver, der før blev separat udført af forskellige medier og fordi Internettet er en del af menneskers hverdagsliv og arbejdsrelaterede aktiviteter. Vidensorganisationens sociale ansvarlighed består bl.a. i at bestemme, hvilke søgeindgange et dokument skal have set i forhold til, hvilke praksisser disse skal være med til at optimere (se f.eks. Hjørland \& Kyllesbech Nielsen, 2001), samt hvilke søge- og navigeringsmuligheder der skal være til rådighed. Ikke alle søgeindgange er nødvendigvis $\emptyset n-$ skelige for alle typer tekster (trykte eller elektroniske). Indeksøren må bestemme, hvilke søgeindgange der er egnede til diverse typer af tekster. Indeks $\varnothing$ rens bliver derfor meget lig den rolle, Finnemann tilskriver hypertekstforfatteren:

„,...the role of the [hypertext-]author is to reduce the unlimited optional freedom to a set of reasonable, or attractive, motivated choices, all of which should be worth to pursue - at least if one actually want the user to utilize the possible options." (Finnemann 1999b, p. 27)

Vidensorganisation kan på denne led ikke fritage sig for en værdiladet tilgang til sin praksis. Dette er imidlertid ikke en dårlig ting. Det er en anerkendelse og udnyttelse menneskets fortolkningsevner og tvinger vidensorganisation til at tage del i det sociopolitiske spil med hensyn til at forme viden for at være behjælpelig med at sørge for ,the best textual means to an end" (Wilson, 1968, p. 21). Ellers kan vidensorganisationens sociale ansvarlighed ikke redegøres for og et argument for dets kvalitative forskel bliver over adisk. Fra en anden vinkel betragter Bolter (2001) computeren og hvad han kalder for 'electronic writing' som en næsten naturlig konsekvens af skrifthistorien. Bolter mener, at computeren og dens hypertekstbegreb må ses som en naturlig udvikling af skriften og som et radikalt brud med tekstlinearitet, som skriften og bogtrykkerkunsten har fremmanet sammen med dets ind ydelse på form-indholdsaspektet. Computeren og hypertekstbegrebet knytter sig til skriftens tekniske natur. Men den væsentlige forskel er den, at hypertekst skaber en radikal måde at designe, organisere og læse tekster på. Dette er hvad, Bolter betragter som en ændring i, hvad han kalder 'writing space'. Dette er på samme tid også problemet med Bolters opfattelse af hypertekstbegrebet. Han argumenterer øjensynligt for, at hypertekst giver læseren en enestående fortolkningsautoritet overfor teksten, som læseren ikke før har haft. På denne led ser Bolter slet ikke, at for at en læser skal kunne være i stand til at læse en tekst på en meningsfuld måde, er denne læser imidlertid afhængig af en (hypertekst)forfatter, der i første omgang har gjort denne læsning mulig. Endvidere, ved at tilskrive læseren den ultimative autoritet i selve læsehandlingen, hæfter Bolter sig ikke ved det faktum, at (hyper)tekster altid bliver produceret indenfor en eller anden form for diskursfællesskab, der er historisk udviklet og som derfor allerede har tildelt teksten betydninger, konventioner og fortolkninger før en specifik læser møder den.

Selvom Bolter ikke har haft Internettet (eller Webben for den sags skyld), som vi kender det i dag i tankerne, så har denne ændring i, hvad han kalder 'writing space', betydning for det biblioteks- og informationsvidenskabelige vidensorganisationsbegreb. Med Internettet og dets mange typer af tekster (og genrer) er det åbenlyst, at hypertekst er et vigtigt aspekt af vidensorganisation. Det er et middel til og en måde at strukturere tekster og genrer på Internettet. På denne måde bliver det biblioteks- og informationsvidenskabelige vidensorganisationsbegreb forbundet med hypertekstualitet og kan derfor siges at ændres til også at dække over organisering og repræ- 
sentation af (hyper)tekster i digitale vidensarkiver. Disse digitale vidensarkiver kan desuden ses som et udtryk for en social organisation af viden fremtvunget af en forvandling i kommunikationsmåderne og midlerne hertil. Internettet er således en naturlig del af ny samfundsmæssig organisering, ligesom det biblioteks- og informationsvidenskabelige vidensorganisationsbegreb er et produkt heraf.

\section{Konklusion}

I denne artikel er der blevet argumenteret for, at det biblioteks- og informationsvidenskabelige vidensorganisationsbegreb er underlagt en bredere social organisation af viden. Begrebets historicitet set $\mathrm{i}$ forhold til samfundets kommunikationsmåder og midler hertil viser, at i det omfang den sociale organisering af samfundet bl.a. er defineret ved dets kommunikationsteknologier, bliver det biblioteks- og informationsvidenskabelige vidensorganisationsbegreb ændret, når en ny kommunikationsteknologi kommer på banen. Ved at belyse det biblioteksog informationsvidenskabelige vidensorganisationsbegreb fra et medieteoretisk perspektiv illustreres det, hvordan begrebet kan ses som en naturlig del af interaktionen mellem medier og kultur. Ved at spore det biblioteks- og informationsvidenskabelige vidensorganisationsbegreb igennem en medieteoretisk optik ses også, at sidstnævnte kan være behjælpelig med at belyse begrebets sociohistoriske natur. Medieteori kan tilbyde vidensorganisationsteori et sociohistorisk perspektiv på diverse mediers rolle i samfundet og hvordan de lagrer og kommunikerer viden. Medieteori tilbyder imidlertid ikke forslag til konkrete, 'praktiske' vidensorganisationsproblemer, men tvinger vidensorganisationsteori til at betragte vidensorganisationsaktiviteter i et bredt sociohistorisk perspektiv. Et sådant perspektiv er nødvendigt, når man skal analysere og evaluere styrker og svagheder ved specifikke måder at organisere viden på i informationssystemer, fordi disse selv samme styrker og svagheder er historisk udviklede. Ét eksempel på dette er den efterhånden klassiske debat om brugen af henholdsvis kontrollerede og ukontrollerede vokabularer i vidensorganisation. (se f.eks. Rowley, 1994). Denne debat kunne ikke foregå uden til rådigheden af bestemte teknologier til organisering af viden.

Skriften, trykkepressen og computeren har igennem historien frembragt betydelige sociale og kulturelle forandringer i de moderne samfund, der har frembragt forandringer i den sociale organisation af viden. Det har disse teknologier gjort ved at fremme nye måder at producere, kommunikere, lagre, genfinde og organisere viden på. Skriften, trykkepressen og computeren/Internettet har på denne led alle bidraget til ændringer i det biblioteks- og informationsvidenskabelige vidensorganisationsbegreb. I mundtlige kulturer er vidensorganisation og social organisering sammen ettet, fordi disse kulturer ikke er i besiddelse af midler til lagring af viden, der lægger udenfor dem som besidder denne viden. Med skriften bliver denne eksternalisering af viden mulig og den sociale organisering bliver formidlet igennem brugen af skriften i diverse sociale praksisser. Trykkepressen frembragte en ny medieindustri, der forsynede samfundet med en mangfoldighed af tekster. Tekster blev omstruktureret som følge af de nye principper for organisering som f.eks. alfabetisering, som bl.a. blev brugt i indekser. Computeren er i stand til at lagre og organisere tekster på en måde, der forøger deres genfindelighed og måden, hvorpå viden kan organiseres i digitale arkiver på Internettet ved at gøre brug af forskellige potentielle søgeindgange. Som en konsekvens, er dette forhold mellem kommunikationsteknologier og det biblioteksog informationsvidenskabelige vidensorganisationsbegreb i konstant sociohistorisk interaktion.

Ved at analysere det biblioteks- og informationsvidenskabelige vidensorganisationsbegreb i forbindelse med forskellige måder at kommunikere på er blevet forsøgt at argumentere for, at dette smalle begreb om vidensorganisation altid er en del af en bredere menneskelig aktivitet, som udtrykker en social organisation af viden, der er historisk betinget. Dette bør erkendes i vidensorganisationsforskning indenfor biblioteks- og informationsvidenskab. Ellers bliver vores begreb om vidensorganisation for abstrakt 
og afskåret fra de kommunikative aktiviteter, som det tjener. Således er det biblioteks- og informationsvidenskabelige vidensorganisationsbegreb i interaction med og a edt af den sociale organisation af viden. Dette viser, at en relevant sociohistorisk baggrund og ramme for det biblioteks- og informationsvidenskabelige vidensorganisationsbegreb er, hvordan mennesker har organiseret deres intellektuelle aktiviteter ved hjælp af forskellige former for kommunikationsmåder og midler hertil.

\section{Litteratur}

Albrechtsen, H. \& Jacob, E. K. (1999). The Dynamics of Classification Schemes as Boundary Objects in Electronic Libraries. Library Trends 47(2), 293-312.

Anderson, J. D. (1996). Organization of Knowledge. In: J. Feather \& P. Sturges (Eds.), International Encyclopedia of Library and Information Science (pp. 336-353). London \& New York: Routledge.

Bazerman, C. (1988). Shaping Written Knowledge. The Genre and Activity of the Experimental Article in Science. Wisconsin: The University of Wisconsin Press.

Bliss, H. E. (1929). The Organization of Knowledge and the System of the Sciences. New York: Henry Holt and Co.

Bolter, D. J. (2001). Writing Space. The Computer, Hypertext, and the Remediation of Print. New Jersey: Lawrence Erlbaum Associates, Publishers.

Bowker, G. C. \& Star, S. L. (1999). Sorting Things Out. Classification and its Consequences. Cambridge, Massachusetts, London: MIT Press.

Burke, P. (2000). A Social History of Knowledge. From Gutenberg to Diderot. Cambridge: Polity Press.
Egan, M. \& Shera, J. H. (1952). Foundations of a Theory of Bibliography. Library Quarterly. Vol. 22(2), 125-137.

Eisenstein, E. L. (1979). The Printing Press as an Agent of Change. Communications and Cultural Transformations in Early-Modern Europe.

Vol. 1-2. Cambridge: Cambridge University Press.

Finnemann, N. O. (1999a). Modernity Modernised - The Cultural Impact of Computerisation. In: Paul A. Mayer (ed.) Computer Media and Communication - A Reader, pp. 141-160. Oxford University Press (http://www.hum.au.dk/ckulturf/pages/publications/ nof/modernity.htm)

Finnemann, N. O. (1999b). Hypertext and the Representational Capacities of the Binary Alphabet. Arbejdspapirer no: 77-99, pp. 1-36, Centre for Cultural Research, Aarhus. (http://www.hum.au.dk/ ckulturf/pages/publications/pages/publications/nof/ hypertext.htm)

Foucault, M. (1979). What Is an Author? In: Textual Strategies. Perspectives in Post-Structuralist Criticism. Ed. Josué V. Harari. Cornell: Methuen \& Co. Ltd.

Gaur, A. (1994). Writing and Library Development. In: Encyclopedia of Library History. Ed. By Wayne A. Wiegand and Donald G. Davis, pp. 659-661. New York: Garland.

Goody, J. (1977). The Domestication of the Savage Mind. Cambridge: Cambridge University Press.

Goody, J. (1986). The Logic of Writing and the Organization of Society. Cambridge: Cambridge University Press.

Goody, J. (1987). The Interface Between the Written and the Oral. Cambridge: Cambridge University Press.

Goody, J. (2000). The Power of the Written Tradi- 
tion. Washington and London: Smithsonian Institution Press.

Goody, J. \& Watt, I. P. (1963). The Consequences of Literacy. Comparative Studies in Society and History, 5, 304-345.

Hagler, R. (1997). The Bibliographic Record and Information Technology. 3th Edition. American Library Association: Chicago

Hansson, J. (1996). In My Mind's Eye - In Search of the Mimetic Relation Between a Library Classification System and its Social Discourses. In: Peter Ingwersen og Niels Ole Pors (red.): Proceedings CoLIS 2: Second international conference on conceptions of library and information science: Integration in perspective. pp. 99-115. Copenhagen: Royal School of Librarianship.

Hansson, J. (1999). Klassifikation, Bibliotek och Samhälle: En Kritisk Hermeneutisk Studie av "Klassifikationssystem för Svenska Bibliotek". Borås: Valfrid. - (Skrifter från Valfrid; 19). (English summary: http://www.hb.se/bhs/personal/joacim/ summary.htm)

Hjørland, B. (1992). The Concept of "Subject" in Information Science. Journal of Documentation. 48(2), 172-200.

Hjørland, B. (1994). Nine Principles of Knowledge Organization. pp. 91-100. In: Knowledge Organization and Quality Management: Proceedings of the third ISKO conference, 20-24 June 1994, Copenhagen, Denmark. Ed. By Hanne Albrechtsen and Susanne Ørnager. INDEKS: Frankfurt/Main.

Hjørland, B. (1997). Information Seeking and Subject Representation: An Activity-Theoretical Approach to Information Science. Westport, Connecticut, London: Greenwood Press.

Hjørland, B. (1998). The Classification of Psychology: A Case Study in the Classification of a Knowled- ge Field. Knowledge Organization, 24(4), 162-201.

Hjørland, B. \& Albrechtsen, H. (1999). An Analysis of Some Trends in Classification Research. Knowledge Organization, 26(3), 131-138.

Hjørland, B. \& Kyllesbech Nielsen, L. (2001). Subject Access Points in Electronic Retrieval. In: M. E. Williams (Series. Ed.), Annual Review of Information Science and Technology: Vol. 35, pp. 249-298. Medford, NJ: Information Today for American Society for Information Science.

Innis, H. A. (1995). The Bias of Communication. University of Toronto Press

Jacob, E. K., \& Shaw, D. (1998). Sociocognitive Perspectives on Representation. In: M. E. Williams (Series. Ed.), Annual Review of Information Science and Technology: Vol. 33, (pp. 131-185). Medford, NJ: Information Today for American Society for Information Science.

Karpatschof, B. (2000). Human Activity. Contributions to the Anthropological Sciences from a Perspective of Activity Theory. København: Dansk Psykologisk Forlag.

Lancaster, F. W. (1998). Indexing and Abstracting in Theory and Practice. $2^{\text {nd }}$ Edition. London: Library Association Publishing

Mai, J. E. (2000). Likeness: A Pragmatic Approach. In: Dynamism and Stability in Knowledge Organization. Advances in Knowledge Organization, vol. 7: 23-27. Proceedings of the Sixth International ISKO Conference, 10-13 July 2000. Toronto, Canada. Ed. By Clare Begthol, Lynne C. Howarth, and Nancy J. Williamson. Ergon Verlag.

Meyrowitz, J. (1994). Medium Theory. pp. 50-77. In: Communication Theory Today. Ed. David Crowley \& David Mitchell. Cambridge: Polity Press. 
Olson, H. A. (1999). Exclusivity, Teleology and Hierarchy: Our Aristotelean Legacy. Knowledge Organization, 26(2), 65-73.

Ong, W. J. (1982). Orality and Literacy. The Technologizing of the Word. London: Routledge.

Rose, M. (1993). Authors and Owners. Harvard University Press.

Rowley, J. (1992). Organizing Knowledge: An Introduction to Information Retrieval. $2^{\text {nd }}$ Edition. Aldershot: Gower

Rowley, J. (1994). The Controlled Versus Natural Indexing Languages Debate Revisited: A Perspective on Information Retrieval Practice and Research. Journal of Information Science, 20 (2), 108-119.

Siskin, C. (1998). The Work of Writing: Literature and Social Change in Britain, 1700-1830. Baltimore and London: Johns Hopkins University Press.

Stockwell, F. (2001). A History of Information Storage and Retrieval. McFarland \& Company, Inc., Publishers.
Svenonius, E. (2000). The Intellectual Foundation of Information Organization. ( $\left.1^{\text {st }} \mathrm{ed}\right)$. Cambridge, Massachusetts, London: MIT Press.

Warner, J. (2001). Information, Knowledge, Text. Lanham, MD: Scarecrow Press.

Wilson, P. (1968). Two Kinds of Power. An Essay on Bibliographical Control. Berkeley, Los Angeles, London: University of California Press.

Wilson, P. (1977). Public Knowledge, Private Ignorance. Toward a Library and Information Policy. Westport, Connecticut, London: Greenwood Press.

Wilson, P. (1983). Second-Hand Knowledge. An Inquiry Into Cognitive Authority. Westport, Connecticut, London: Greenwood Press.

Woodmansee, M. (1994). On the Author Effect: Recovering Collectivity. In: The Construction of Authorship: Textual Appropriation in Law and Literature. Ed. Martha Woodmansee and Peter Jaszi. Durham, North Carolina: Duke University Press. 